\title{
DEMIXING KINETICS OF PHASE SEPARATED POLYMER SOLUTIONS IN MICROGRAVITY
}

\author{
D E Brooks \\ S B Bamberger \\ J M Harris \\ Depts of Pathology \\ Dept of Neurology \\ Dept of Chem1stry \\ and Chemiatry \\ Oregon Health \\ University of \\ Univeraity of B.C. \\ Sciences University \\ Alabama \\ Vancouver, Canada \\ Portland OR, USA \\ Huntsuille AL, USA \\ J Van Alstine \& R S Snyder \\ Space Sclencea Laboratory \\ Marshall Space Flight Center AL, USA
}

\section{ABSTRACT}

Phase-geparated solutions of tro neutral polymers in buffer provide a useful and versatile medium for the partition separation of blological cells. Hovever, the efficiency of auch separations is orders of magnitude lover than the thermodynamic limit. To teat the hypothesis that this ineficiency is at least partially due to the convection and sedimentation that occur during the gravity-driven demixing that follovs introduction of cells to the oystems, we have begun a series of experiments aimed at performing cell partition in a lov $g$ environment. We have studied demixing of loopycnic three polymer-solvent systems, performed experiments on KC-135 alrcraft and completed one shuttle mid-deck experiment. Analysis of the results of these experiments and comparisons with the predictions of acaling relations for the dependence of phase domain aize on time, derived for a number of possible demixing mechanisms, are presented.

\section{INTRODUCTION}

When two neutral polymers such as dextran and poly(ethylene glycol) (PEG) are mixed at constant temperature in aqueous solution above a set of critical concentrations tro phases are formed. These have proven useful as partition media for the aeparation of a ride varlety of blological macromoleculea, organelles and cells $(1,2)$. If the species to be separated are larger than a fev hundred angstroms in diameter the distributions take place betveen one of the bulk phases and the interface betreen them, rather than between the two bulk phases as occurs vith molecular partition. This 18 possible because the interfacial tension between the phases is extremely lov (typically $\leq 10$ $\mu \mathrm{N} / \mathrm{m})$, resulting in relatively reak adsorption of particulates in the interface.

Our principle interest in the present context is in the separation of cella. In this case it 18 clear that the partition behavior, 1 . $e$. the fraction of a population which is adsorbed at the interface as opposed to being suspended in one of the bulk phases, is determined by the surface properties of the celle and the manner in which these properties determine the interaction 
between the cell and the two phases. To a major degree this interaction can be tailored through choice of the constituents of the tro phase system. For instance, including certain salts such as phosphates or citrates in the mixtures produces a type of Donnan potential difference between the bulk phases which provides an electrostatic contribution to the free energy of adsorption of the cell at the interface (3). Hence, separations based on surface charge differences can be achieved. Similarly ligands, such as antibodies, which exhibit a high affinity for a surface feature on the cell subpopulation of interest can be modified by coupling one of the phase polymers to them and be included in the system. The polymer-modified ligands vill then exhibit a strong preference for the phase in which that polymer is concentrated. Hence their binding to the targeted cells will result in that subpopulation partitioning into the phase in which the modified ligand accumulates, leaving, in optimal circumstances, the remaining cells adsorbed at the phase boundary $(4,5)$.

The above picture implies that the free energy of adsorption, 1.e., the decrease in free energy which occurs when the cell adsorbs at the interface between the tro phases, $\Delta G^{\circ}$, should be the only characteristic of the system which determines the partition behavior. If thermodynamic equilibrium prevails the partition coefficient, $K$, (defined as the ratio of the number of cells free in the bulk phase to the number adsorbed at the interfacel should be determined only by the free energy of adsorption and the temperature. Quantitatively, $K$ should be given by the Boltzmann expression:

$$
K=\exp \left[-\Delta G^{\circ} / k T\right]
$$

where $k$ is Boltzmann's constant and $T$ is the absolute temperature. This equation predicts that in order to observe values of $K$ in the range that is useful experimentally, (0.2 to 5 , say) $\Delta G^{\circ}$ must be vithin a factor of \pm 2 of kT.

The above prediction has been tested $(4,5)$. Without going into details, it is possible to calculate $\Delta G^{\circ}$ if the equilibrium contact angle formed betveen the surface of a cell and the interface betreen the phases can be measured for a representative population of cells adsorbed at the phase boundary. By varying features such as the Donnan potential between the phases, the interfacial tension and the concentration of polymer-derivatized affinity ligand it is possible to vary the contact angle, and hence $\Delta G^{\circ}$, over a vide range. The partition coefficients are meagured independently for each set of conditions and the predictions of the Boltzmann expression tested. The remarkable result is that $K$ depends approximately exponentially on $\Delta G^{\circ}, a s$ predicted, but the apparent value of $k T$ is several orders of magnitude greater than the actual value. This, along with other results discussed in (4), demonstrates that partition is a stochastic process but its characteristic energy is much larger than thermal energies. Put another vay, a random selection of the cells which, on the basis of their adsorption free energy would be expected to be found at the interface folloving a distribution experiment, have been removed from that location and released into the bulk phase by forces which are not thermal in origin.

The forces responsible for removing cells from the interface have not been identified. We hypothesize, hovever, that they result from the complex hydrodynamic environment to which adsorbed cells are exposed as the cells are mixed with the phase system and the resulting emulsion alloved to settle and demix. The two bulk phases, which differ in density, collect at the bottom and top of the container chiefly via strong convective streams which in turn 
set up secondary flows, creating a chaotic environment which produces relatively strong, unsteady shear forces. In addition, following the convection, sedimentation and flotation of phase droplets vith cells adsorbed to their surfaces also occurs. At any stage in the demixing, then, fluid shear forces are present which may be responsible for the removal of cells from the phase boundary to which they are adsorbed. The goal of our program of space experiments, therefore, is to study partition in the absence of appreciable convection and sedimentation and to see how closely the partition process approaches thermodynamic behavior under these conditions.

\section{PHASE DEMIXING EXPERIMENTS}

One obvious problem with the above approach is the possibility that in the absence of significant gravitational forces the tro phase systems, once emulsified, may not demix in an acceptable length of time. This seemed to be a very real possibility before we began our experiments since otto and Lacy (6) had reported that oll and vater emulsions were extremely stable in a reduced gravity environment, shoving no sign of demixing over a period of many hours. As a first step tovards performing partitioning experiments in space, therefore, we have begun to study the demixing of mixed two phase polymer systems in the absence of appreciable gravitational effects.

Our work in this area to date has been of three types: studies on the demixing of an leopycnic two phase system containing three polymers in water; short term lov $g$ experimenta on $\mathrm{KC}-135$ aircraft and a single shuttle mid-deck experiment flown in April, 1985. In all three cases the experimental approach has been simply to $\mathrm{mix}$ the systems manually and to observe and photograph them as they demix vith time.

\section{Experimental}

The polymers vere obtained from Pharmacia (dextran; Ficoll) and Union Carbide (PEG, Sentry Grade). Their approximate molecular veights are given in Table 1 where the compositions of the systems studied along with some of their physical properties are listed. The methods for making up and characterizing the phase systems are fully described in Chapter 3 of reference 2. Typical phase diagrams for the systems used are given in (1).

\section{Results of Ground Experimentation}

The first aystems examined vere the isopycnic mixtures of dextran, Ficoll and PEG. While these systems are rather viscous and not generally useful for cell partitioning work they did prove to adequately model the behavior of dextran/PEG syetems in microgravity. Demixing of these syatems occurred over a period of approximately $10 \mathrm{~min}$ following mechanical mixing at constant temperature. Microscopically, domains of each phase could be detected 2 s after mixing. As the domains grew, reducing the area of interface, they formed three dimensional bicontinuous structures which eventually evolved into a central, dextran-rich phase surrounded by the Ficoll/PEG-rich phase. The latter phase spreads on the poly(methyl methacrylate) chamber vall when both phases are exposed to the plastic. Characteristic photographs taken over the first four minutes of demixing are shown in Fig. 1. 
Table 1

\begin{tabular}{|c|c|c|c|c|c|c|c|c|}
\hline $\begin{array}{l}\text { Composition } \\
(\% \mathrm{w} / \mathrm{w}) \\
\text { (DEX/PEG/FIC) }\end{array}$ & salt & $\begin{array}{c}\text { Dextran } \\
\text { Type }\end{array}$ & $\begin{array}{l}\text { V1scos } \\
\text { Top }\end{array}$ & $\begin{array}{l}\text { ty (CP) } \\
\text { Bottom }\end{array}$ & $\begin{array}{c}\text { Interfacial } \\
\text { Tension } \\
(\mathrm{uN} / \mathrm{m})\end{array}$ & $\begin{array}{l}\text { Density } \\
\text { Top }\end{array}$ & $\begin{array}{l}(\mathrm{g} / \mathrm{ml}) \\
\text { Bottom }\end{array}$ & $\begin{array}{l}\text { Tie Line } \\
\text { Length } \\
(* w / w)\end{array}$ \\
\hline$(5 / 3.5 / 0)^{a}$ & I & T500 & 3.36 & 24.6 & 5.24 & 1.0263 & 1.0563 & 9.41 \\
\hline$(5 / 4 / 0)^{a}$ & $\mathbf{I}$ & T500 & 3.41 & 32.1 & 10.54 & 1.0281 & 1.0566 & 20.97 \\
\hline$(6 / 4 / 0)^{a}$ & I & T500 & 3.76 & 44.3 & 19.22 & 1.0286 & 1.0545 & 11.59 \\
\hline$(8 / 4 / 0)^{a}$ & $I$ & T500 & 4.38 & 69.1 & 34.71 & 1.0239 & 1.0697 & 14.11 \\
\hline$(7 / 5 / 0)^{a, b}$ & II & $\mathrm{T} \mathbf{4 0}$ & 4.96 & 12.2 & 6.00 & 1.0277 & 1.0578 & 11.69 \\
\hline$(5.5 / 0.67 / 9.5)^{c . d}$ & I I I & T500 & 39.6 & 19.4 & 3.9 & 1.072 & 1.072 & $N D^{e}$ \\
\hline$(7 / 0.29 / 12)^{a, c, d}$ & I I I & T500 & ND & ND & 16 & 1.085 & 1.085 & ND \\
\hline
\end{tabular}

Composition and physical properties of phase systems with equal volumes of each phase containing the polymers dextran (DEX), poly (ethylene glycol) MW 8000 (PEG) and Ficoll 400 (FIC), (MW 400,000). Salt concentrations: $109 \mathrm{mM} \mathrm{N} \mathrm{HPO}_{4}, 35 \mathrm{mM} \mathrm{NaH} \mathrm{PO}_{4}, \mathrm{pH} 7.2$ (I); 150 mM NaCl,

$7.3 \mathrm{mM} \mathrm{Na} \mathrm{HPO}_{4}, 2.3 \mathrm{mM} \mathrm{NaH} \mathrm{PO}_{1} \mathrm{pH} 7.2$ (II); $84.6 \mathrm{mM} \mathrm{Na} \mathrm{HPO}_{4}, 25.4 \mathrm{mM} \mathrm{NaH}_{2} \mathrm{PO}^{\prime}$,

$\mathrm{pH} 7.5$ (III). ${ }^{\prime}$ Ali dextran fractions have $M_{w}^{\prime} \sim 500,000$ except the (7/5/0) ${ }^{2}$ system which contains a fraction with $M_{W} \sim 40,000$.

System flown during space shuttle flight 51-D.

System flown on $\mathrm{KC}-135$ aircraft.

Isopycnic system at $1 \mathrm{~g}$.

The phase properties of the 1sopycnic systems are listed as follows: the Ficoll-rich

phase in "Top" column, the dextran-rich phase in "Bottom" column.

e ND: not determined.

DROPLET GROWTH IN ISOPYCNIC SYSTEM

5.5 Jextran T500,9.5 Ficoll $400.0 .665 \%$ PE 8000. $0.11 \mathrm{M}$ Sodium Phosphate pH 7.5

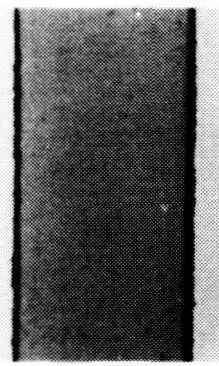

$10 \mathrm{sec}$

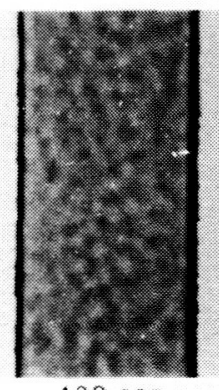

120 sec

tramber Domensions

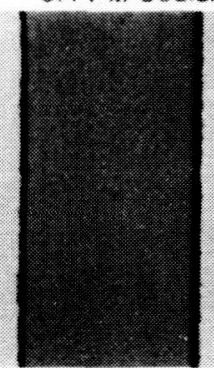

$30 \mathrm{sec}$

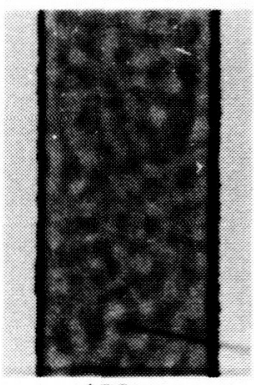

$150 \mathrm{sec}$

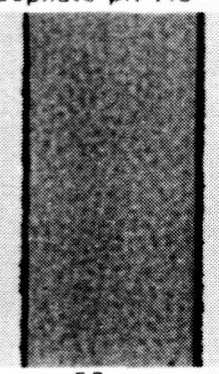

$50 \mathrm{sec}$

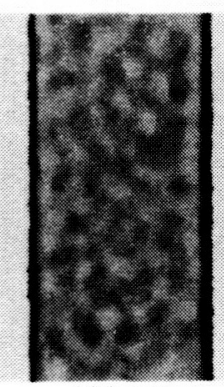

$180 \mathrm{sec}$

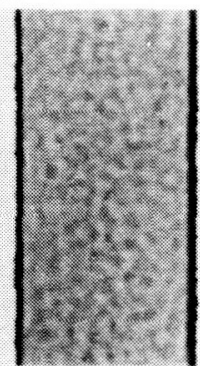

$90 \mathrm{sec}$

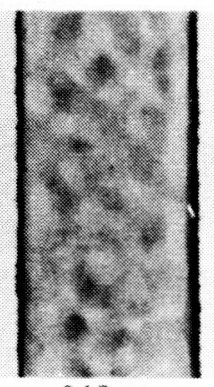

240 sec

Height $50 \mathrm{~mm}$ Width $10 \mathrm{~mm}$ Depth $2.5 \mathrm{~mm}$

Figure 1. Grovth of phase domains during the first $4 \mathrm{~min}$ of demixing of the (5.5/.67/9.5) 18opycnic system described in Table 1. 
To provide a measure of the rate of demixing, an estimate of the projected areas of the domains of each phase vas made as a function of time after mixing. Slides taken at each time vere projected, the outlines of connected domains traced and the area of each domain estimated following manual digitization. An example of the result at each stage is illustrated in Fig. 2 where the distribution of the drop areas measured is also given. The mean area at each time was used to calculate the radius of a circle of equivalent area to provide a characteristic linear dimension. The data, presented as a log-log plot, 18 shown in Fig. 3. The slope of this plot provides the power lav coefficient which can be used to characterize the demixing rate.
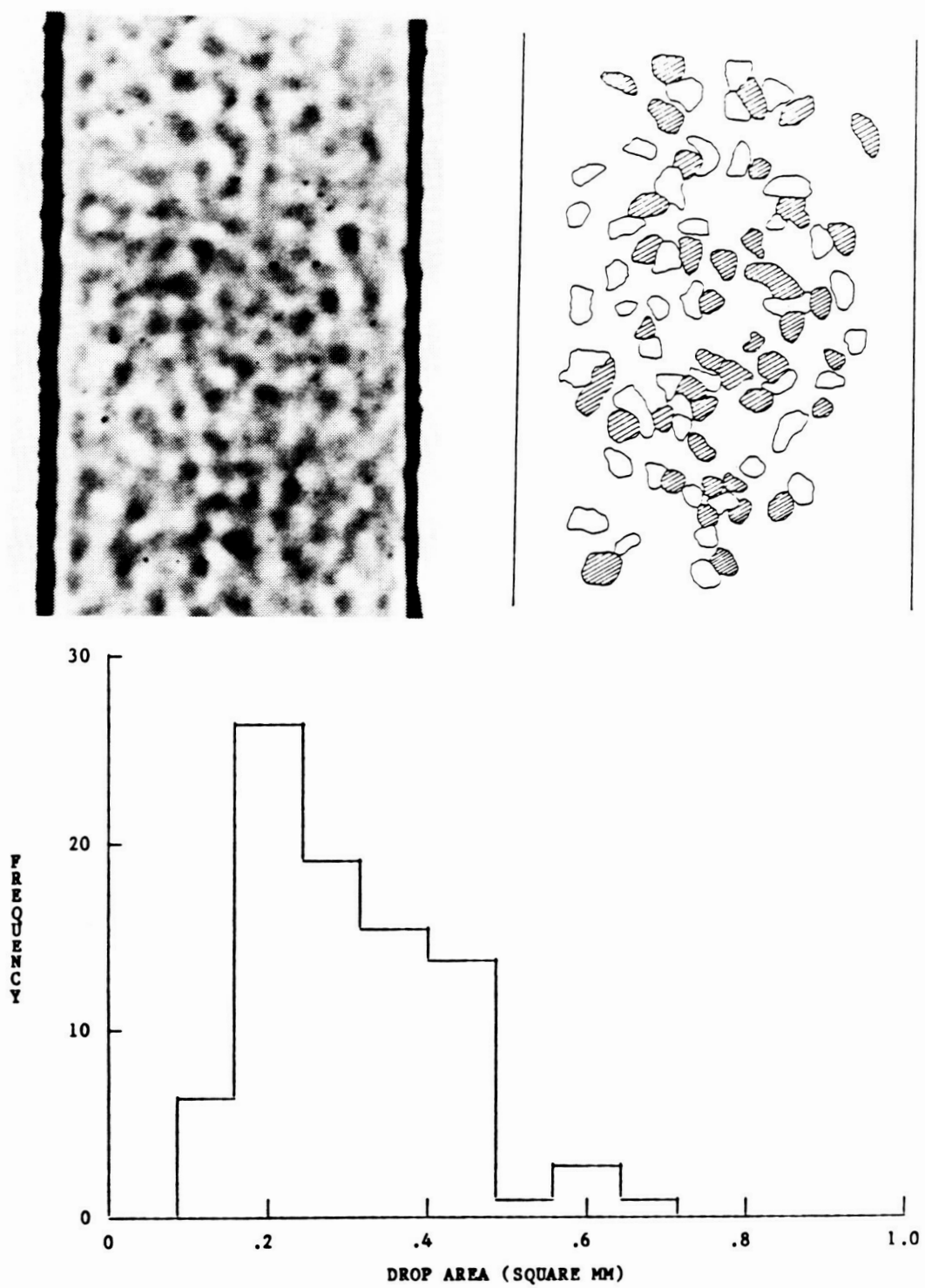

Figure 2. Isopycnic system (5.5/.67/9.5) 90 s after mixing, showing tracing of domains and frequency histogram of areas.

\section{Results of Flight Experiments}

An indication of the behavior to be expected with partitioning was obtained by observing the early systems of use in cell stages (first $20 \mathrm{~s}$ ) of 
demixing of dextran/PEG systems on KC-135 aircraft undergoing parabolic flight profiles. Qualitatively similar results to those seen with the isopycnic systems were obtained. The results were quite consistent from experiment to experiment, as shown by the overlapping of the data from three parabolas included in Fig. 3. The system illustrated in Fig. 3 demixed more rapidly than the isopycnic systems studied, perhaps because of the lover viscosities of the phases (Table 1 ).

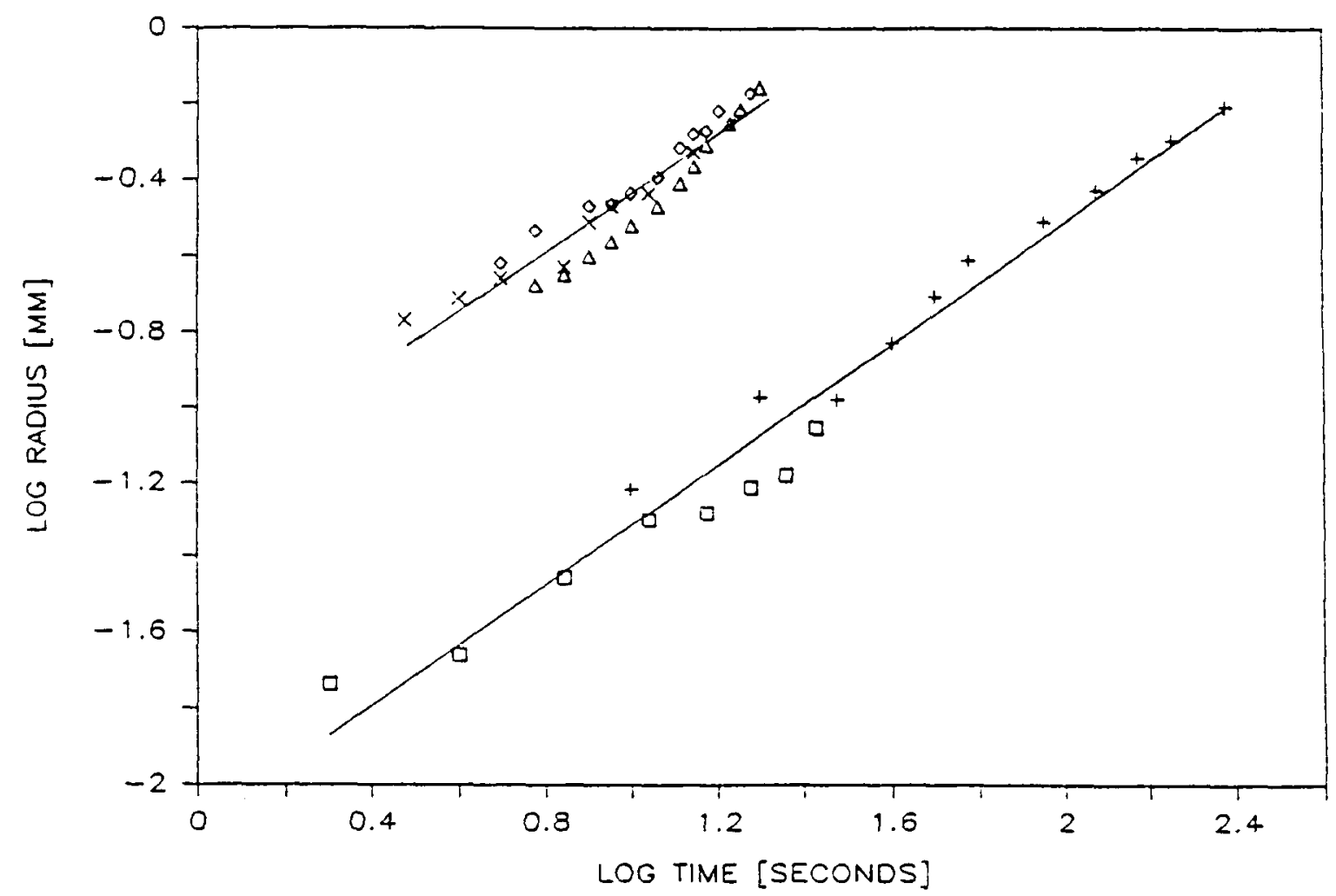

Figure 3. Log-log plot of characteristic length us time for three KC-135 experiments on the (7/5/0) syaten (upper) and for the (5.5/.67/9.5) isopycnic system at $1 \times g$.

In Apri1, 1985 on miseion 51-D experiment PPE-1 vas performed in which the time course of demixing vas observed and photographed for a series of dextran/PEG systems as vell as for one of the 1sopycnic mixtures, included as a control. The systems vere contained in a small plastic box (10 x $13 \times 3$ $\mathrm{cm})$ containing 15 transparent chambers $(1.5 \times 1.8 \times 1.0 \mathrm{~cm})$, each of which contained a stainless steel mixing ball as vell as a tro phase mixture. At the beginning of the experiment the box vas shaken manually, the action of the steel balls being sufficlent to emulsify each sample. The box was then taped to a fluorescent light box and photographed at appropriate times over a period of $110 \mathrm{~min}$ to record the evolution of the demixing. The time at which each exposure vas made vas printed directly on the film by the data back of the camera.

The control experiments performed on the ground are illustrated in Fig.4. The contents of the ten chambers illustrated are given below, using the designations defined in the legend to Table 1; the final fraction in the 
description of each sample indicates the ratio of PEG-rich to dextran-rich phase volume. First row, left to right: (8/4/0)I, 2/3; $(8 / 4 / 0) I, 3 / 2$; (7/0.29/12)III, 1/1; (7/5/0)II, $1 / 1$ and $(7 / 5 / 0) I I, 1 / 1$. Second rov, left to right: $(8 / 4 / 0) I$, $1 / 1 ;(6 / 4 / 0) I, 1 / 1 ;(5 / 4 / 0) I$, 1/1; (5/3.5/0)I, 1/1 and (5/4/0)I, 1/1. All phase systems contained $0.05 \mathrm{mg} / \mathrm{ml}$ Trypan Blue (rhich accumulates in the PEG-rich phase) except the last chamber in each rov which

glutaraldehyde-fixed contained erythrocytea.

Representative photographs taken from the space experiment are shown in Fig. 5. Qualitatively, comparison with the control experiment shovs that in all cases demixing occurred more rapldly on the ground than in space. Hovever, the systens (5/3.5/0; 5/4/0; 7/0.29/12) characterized by values of interfacial tension and viscosities typical of those useful for cell partitioning on earth demixed vith a time course consistent with the requirements. Systems comprised of higher polymer concentrations, with larger differences in concentration between the phases $(6 / 4 / 0$; $8 / 4 / 0)$, vere much slover to demix. The phase volume ratio also had a strong effect on the demixing rate in the $(8 / 4 / 0)$ system. Interestingly, the chamber with the $1 / 1$ mixture did not demix as soon as did that containing the lover amount of PEG-rich phase. In the sample in wich this ratio vas reversed, no visible demixing occurred over the time course of the experiment.

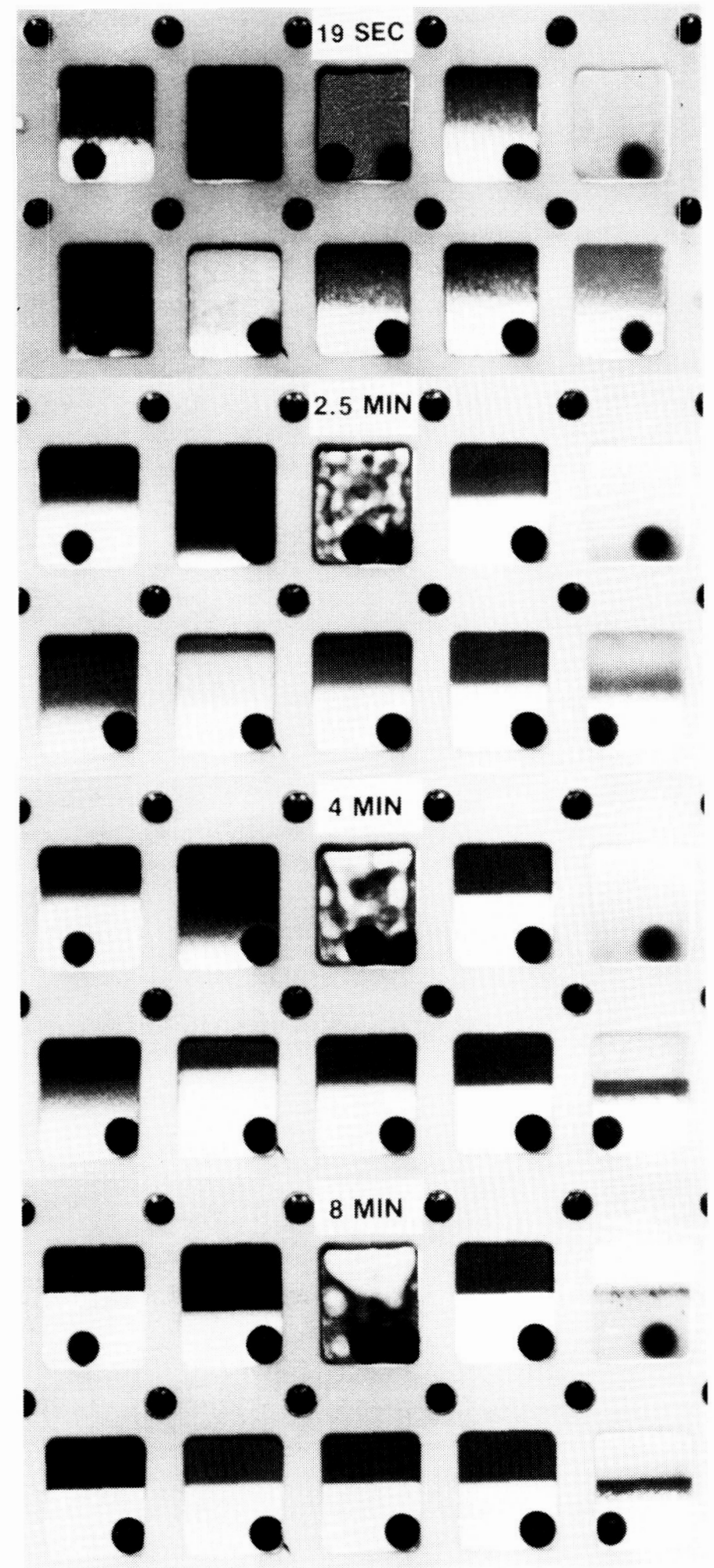

Figure 4. Control $1 \times g$ demixing experiment for PPE-1; see text for description of the systems. 
ORIGINAL PAGE IS

OF POOR QUALITY
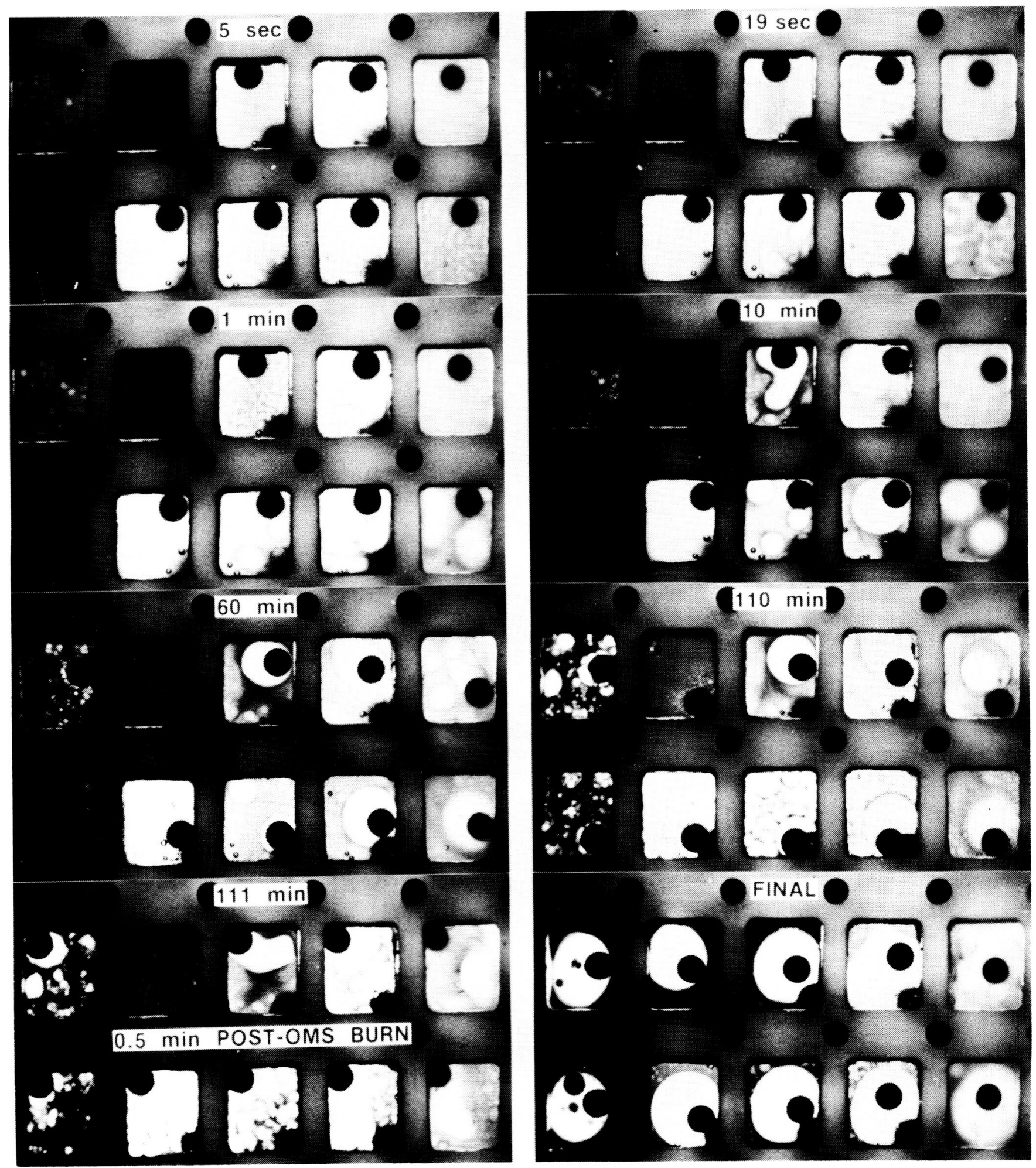

Figure 5. Photographs from PPE-1 experiment carried out on STS 51-D taken at times after mixing indicated; see text. 
The disposition of the localized phases vas as expected based on the spreading of the PEG-rich phase on the chamber vall. That is, in every sample, after six days in orbit, before the systems vere mixed (the photograph marked FINAL in Fig. 5) the PEG-rich phase vas located adjacent to the chamber valls vith the dextran-rich phase displaced into an "egg yolk" in the interior of the chamber. ". The steel mixing balls, on which the dextran-rich phase spread, were found within that phase in every case.

The presence of particulates (fixed erythrocytes) had no effect on the demixing rate in one case $(5 / 4 / 0)$ but appeared to reduce the rate in the other system $(7 / 5 / 0)$. This experiment needs to be repeated; the reason for the observed behavior is not clear at present.

The final noteworthy feature of the PPE-1 experiment is the apparent shift in chemical equilibrium which became evident about 15 to $20 \mathrm{~min}$ after shaking. Under laboratory conditions, once the phases demix they remain stable and of constant composition indefinitely. The PPE-1 photographs clearly show a change in composition of the localized, PEG-rich phases from $30 \mathrm{~min}$ onvards, seen as a further decomposition of the fairly uniform dark regions into mottled areas of demixing. We have never observed a phenomenon like this on the ground unless a change in the experimental conditions, such as dilutior concentration through evaporation or a temperature shift occurred. In any of these cases the shift in equilibrium results in a change in composition of each of the phases, presumably in the present instance by the mechanism of spinodal decomposition since the syatems flown lie vell within the binodal. It seems very probable that the secondary decomposition observed in the PPE-1 experiment vas due to a temperature increase. It vas found after the flight that the surface of the light box increased in temperature by $9^{\circ} \mathrm{C}$ in $30 \mathrm{~min}$, the likely source of the temperature change. For this reason the kinetic analysis discussed below vas carried out where possible on data generated from photographs taken during the first ten minutes of the experiment.

\section{DISCUSSION}

It is clear from the above results that the polymer phase systems demix much more rapidly in microgravity than did the oll/water mixtures flown by others (6). In spite of the fact that the latter systems vere characterized by interfacial tensions orders of magnitude larger than those typical of the systems studied here. The observed demixing rates are, in most cases, quite compatible with the times over wich cells retain viability and separation experiments can be run $(1,2)$. Hovever, in all cases, demixing in a one $g$ environment occurred much more rapidly than vas observed in the sensible absence of gravitational effects. Even vithout the effects of a density difference the localized phases vere relatively atable in microgravity as shown in the $111 \mathrm{~min}$ panel in Fig. 5. This frame shovs the appearance of the samples folloving a sudden acceleration produced by the orbital maneuvering system. Even though all the mixing balls have clearly been ohifted the systems have not mixed appreciably.

At present the factors that control the demixing rate in microgravity are not clear. Preferential vetting of the container valls does not geem to have a aignificant effect on the kinetics until the characteristic dimension of the localized phases approaches that of the container. That 18 , the demixing appears to occur uniformly throughout the sample until the process is rell advanced (Fig. 1). As the demixing nears completion, hovever, the disposition of the localized phases 18 determined by which of the tro phases 
spreads over the container vall, the non-spreading one (in our case the dextran-rich phase) then being forced into the center of the chamber. We have not yet studied systems in vhich wall vetting with an intermediate contact angle occurs.

As rould be expected, the phase volume ratio had a strong effect on the demixing, the most rapid separation resulting when the phase which did not spread on the chamber vall was in the majority. When the ratio vas reversed, no demixing ras observed over the time course of the experiment lalthough demixing evidently did occur eventually as shown by the last frame in Fig. 5). The 1:1 combination demixed vith an intermediate time course.

Although it is clear that the demixing rate will depend in some way on the viscosities of the phases and the interfacial tension between them the present experiments do not allow any conclusions to be drawn regarding the form of that dependence. It is obvious from our results that systems contalning higher concentrations of polymers demix more sloviy than those closer to the critical concentrations required for phase separation. Hovever, both the interfacial tension and the phase viscosities increase strongly as the total polymer concentrations are increased so the individual effects of each of these parameters cannot yet be determined.

To obtain a more quantitative assessment of the demixing process, suitable photographs taken on PPE- 1 were analyzed as described above for the isopycnic system and for the $\mathrm{KC}-135$ experiments. The results are given in Table 2 . It

Table 2

\begin{tabular}{|c|c|c|c|c|c|c|}
\hline \multirow[t]{2}{*}{$\begin{array}{c}\text { System } \\
\text { (See Table 1) }\end{array}$} & \multirow{2}{*}{$\begin{array}{l}\text { Pover L } \\
\log r=\end{array}$} & \multicolumn{2}{|c|}{$\begin{array}{l}\text { Lav Parameter } \\
=A+B \log t\end{array}$} & \multicolumn{3}{|c|}{ Exponential Parameters } \\
\hline & & B & r.c. & $r_{0}$ & $\beta$ & $r . c$. \\
\hline \multicolumn{7}{|l|}{ Isopycnic $1 \times g$} \\
\hline$\overline{(5.5 / .69 / 9.5)}$ & -2.11 & 0.80 & 0.985 & 0.052 & 0.014 & 0.757 \\
\hline \multicolumn{7}{|l|}{$\mathrm{KC}-135$} \\
\hline \multicolumn{6}{|l|}{ Shuttle } & 0.968 \\
\hline$(7 / .29 / 12)$ & -1.31 & 0.61 & 0.967 & 0.30 & 0.069 & 0.940 \\
\hline$(7 / 5 / 0)$ & -0.89 & 0.66 & 0.989 & 0.37 & 0.041 & 0.941 \\
\hline$(5 / 3.5 / 0)$ & -0.78 & 0.51 & 0.917 & 0.33 & 0.041 & 0.983 \\
\hline$(6 / 4 / 0)$ & -4.76 & 1.21 & 0.948 & 0.089 & 0.020 & 0.986 \\
\hline$(8 / 4 / 0) \quad 1 / 1$ & -3.5 & 0.79 & 0.857 & 0.083 & 0.00022 & 0.894 \\
\hline$(8 / 4 / 0) \quad 2 / 3$ & -1.31 & 0.26 & 0.987 & 0.20 & 0.00017 & 0.937 \\
\hline$(5 / 4 / 0) \Delta T$ & -18.0 & 4.74 & 0.976 & 0.0069 & 0.00078 & 0.976 \\
\hline
\end{tabular}

Note: Linear dimensions given in $\mathrm{mm}$; data points leading to begt fit parameters had an average standard deviation of $\pm 17 \%$; $r$. c. = linear regression coefficient. For the system designated as $(5 / 4 / 0) \Delta T$ the parameters vere derived from the secondary decomposition of the aystem after the temperature had probably risen (see text). 
should be noted that the temperature vas probably not constant during the period covered by the photographs analyzed for the $5 / 4 / 0,6 / 4 / 0$ and $8 / 4 / 0$ systems, as mentioned above.

Referring to Fig. 3, it is seen that the data obtained over the $20 \mathrm{~s}$ available on $\mathrm{KC}-135$ flights is a reasonable predictor of the behavior up to times at least ten-fold longer. Hence, such experiments can be useful in examining some of the fundamental determinants of the demixing rate in the systems of interest here. The large difference in the initial size of the domains betveen the two types of experiments may relate to the difficulty in mixing the systems thoroughly under the conditions prevailing in the $\mathrm{KC}-135$ experiment.

The mechanisms by which the polymer phases demix are of direct interest to our cell partition vork, as explained in the Introduction. Evidently there has been little work done in this area. Baird (7) has calculated characteristic times for the demixing of tro phase systems of the type used here assuming the coarsening of the emulsion takes place by the mechanism of Ostuald ripening. This is the process whereby diffusion of solute takes place out of small drops and into large ones until all the dispersed phase is centralized in a single drop. His result indicates demixing times of the order of years for our systems, hovever, so this mechanism is clearly not the dominant one.

If it is assumed that the composition of the phases 18 unaffected by the emulsification process and that only the interfacial area and curvature 18 affected, then it seems likely, given the high volume concentration of each phase present, that coalescence between domains will occur during the demixing process. Whether or not this vould be the only mechanism responsible for the localization of the phases is not clear since it is conceivable that extended bicontinuous structures could be formed wich vould then reduce their interfacial area spontaneously, causing localization of the phases. Such structures are observed macroscopically in isopycnic systems in the latter stages of demixing (not shown). The photographs ve have analyzed to date do not provide a definitive answer to this question due to the depth of focus of the camera and the high concentration of interface present early in the process.

If coalescence is the dominant process responsible for demixing, the observations on the dependence of demixing on the volume ratio can be rationalized. When the phase vhich spreads on the chamber wall is in the minority the concentration of drops of the non-spreading phase in the interior of the chamber will be high, increasing the probability of collision and coalescence. When the ratio is reversed, hovever, the dispersed, non-spreading phase vill be at a much lover concentration, reducing the frequency of coslescence events, consistent with the results observed for the $8 / 4 / 0$ system.

If coalescence between dispersed drops of the phases 18 responsible for the observed demixing rates, the question arises regarding vhat processes determine the rate at which the coalescence events take place. We have derived some approximate scaling relations which describe cases in which collisions which lead to drop coalescence are induced by drop diffusion, by externally imposed shear (such as might be present as a residual from the mixing process) and by shear produced by the local flutd disturbance generated by coalescence of two drops (unpublished). In the drop diffusion case the length scale characteristic of the average drop size, $r$, depends on 
the time after mixing, $t$, according to:

$$
r \propto t^{1 / 3}
$$

This dependence 18 also found for Ostwald ripening. If coalescence is produced by externally applied shear:

$$
r \propto \exp [\beta t]
$$

If the shear produced locally by the coalescence of two drops is responsible for inducing further collisions:

$$
r \propto t
$$

The analysis summarized in Table 2 does not provide a definitive ansver as to which of the above relations best fits the data. Hovever, if the systems most likely to have been photographed at constant temperature are considered it is seen that demixing in four of the six (the three isopycnic experiments and the $7 / 5 / 0$ system) is best described by a pover lav and that in these cases the pover lies betveen 0.55 and 0.80 , approaching the value of 1.0 predicted for the coalescence-induced shear case. In the other two systems the exponential fit appears marginally better, supporting the imposed shear interpretation. Obviously, further experimentation is required but the results to date seem consistent vith the idea that coalescence is an important part of the mechanism by vhich phase separated polymer systems demix in the absence of gravitational effects.

\section{ACKNOWLEDGEMENTS}

Th1s work vas supported by contracts from the Microgravity Sciences and Applications Division of NASA. JVA is a Visiting Scientist of the Universities Space Research Association.

\section{REFERENCES}

1. Albertsson P-A 1986, Partition of Cell Particles and Macromolecules, Third edition, Ner York, Wiley-Interscience.

2. Walter H, Brooks DE \& Fisher D 1986, Partitioning in Aqueous Tro Phase Systems. Theory, Methods, Uses and Applications in Biotechnology, Orlando, Academic Press.

3. Brooks D E et al 1984, Electrostatic and electrokinetic potentials in tro polymer aqueous phase systems, J Colloid and Interface Sci. 102, $1-15$.

4. Brooks D E et al 1984, Rationale for tro phase polymer system microgravity separation experiments, Proc. Fifth European Symp on Materials Science Under Microgravity, Schlose Elmau, 5-7 November 1984, ESA SP-222, 315-318.

5. Sharp K A Brooks D E 1987, In preparation. 
6. Lacy L L \& Otto G H. 1975, The stability of liquid dispersions in low gravity. Proc. AIAA-IAGU Conf. on Scientific Expts. of Skylab, AIAA Paper 74-1242, Marshall Space Flight Center, Alabama, November, 1974.

7. Baird, J K 1984, Application of the theory of Ostwald ripening to microgravity experiments, Proc. Fifth European Symp on Materials Science Under Microgravity, Schloss Elmau, 5-7 November 1984, ESA $\mathrm{SP}-222$, 319-324. 